IMAFRONTE-N $\mathrm{N}^{\mathrm{o}} 27.2020$, pp. 1-21

ISSN: 0213-392X / eISSN: 1989-4562

DOI: https://doi.org/10.6018/imafronte.431901

\title{
VICTORIA O MUERTE: MÚSICA PARA LOS ÚLTIMOS MOMENTOS DE EL ÁLAMO EN EL CINE
}

\author{
VICTORY OR DEATH: MUSIC FOR THE LAST MOMENTS OF THE ALAMO \\ IN CINEMA
}

\author{
ÁNGEL JUSTO ESTEBARANZ \\ LUCÍA PÉREZ GARCÍA
}

Universidad de Sevilla

Recibido: 11-06-20 / Aprobado: 28-09-20

\section{RESUMEN}

La defensa y batalla de El Álamo en 1836 supone uno de los grandes acontecimientos de la Historia americana, hito fundacional sobre el que el cine se interesó desde sus primeros momentos, y que ha conocido diversas interpretaciones a lo largo de un siglo (1911-2004). Los momentos más dramáticos fueron las horas previas a la batalla final, tras trece días de asedio de las tropas del general Santa Anna a los texanos, y la propia batalla. El tratamiento musical que los diferentes compositores de la partitura de cada película han dado a estos momentos ha variado en función de diversos factores. En este artículo analizamos la música de las escenas relativas al día previo a la batalla $\mathrm{y}$ al asalto final, abordando especialmente el toque de degüello empleado por cada uno, su importancia en el conjunto de la partitura, sus posibles referentes, su estructura y el carácter del tema. Para ello diseñamos unas tablas de análisis de contenido categorial, que nos permiten comparar las seis películas estudiadas y llegar a las conclusiones.

PALABRAS CLAVE: El Álamo, cine, música cinematográfica, toque de degüello, adaptaciones.

\section{ABSTRACT}

The defense and the battle of The Alamo in 1836 is one of the greatest events of American History. Film writers, directors and producers were interested in it since the early days, so there are several adaptations from 1911 to 2004. The most dramatic moments were the hours before the battle after thirteen days of siege of the Santa 
Anna's troops, and the final assault. According to different factors, each film composer has written a personal version of the music for these scenes. In this paper we analyze the musical treatment applied to the scenes of the previous day and of final assault, highlighting the different versions of the deguello, its importance inside the score, its sources, structure and character. For this we designed some categorical content analysis tables, which allow us to compare the six films studied and reach the conclusions.

KEYWORDS: The Alamo,
cinema, film music, degüello,
adaptations.

\section{INTRODUCCIÓN}

La mañana del 6 de marzo de 1836, en San Antonio de Béjar, las tropas a cargo del general mexicano Antonio López de Santa Anna tocaron a degüello frente a la antigua misión conocida como El Álamo. Durante trece días, 187 texanos aguantaron bombardeos y sufrieron las calamidades del tiempo y el hambre en nombre de la libertad y la independencia de Texas. Victoria o muerte era su lema. Sin piedad, el de los mexicanos.

La batalla de El Álamo significa para la historia de Estados Unidos más que la revolución de Texas. Es, en palabras de Hatch, "un testamento de valor, honor y determinación de personas corrientes que no pudieron resistir la urgencia inherente de buscar la libertad en la tiranía y fueron capaces de sacrificar sus vidas por este privilegio" (Hatch, 2007: 1). Valores más que hechos. Emoción más que historia. Una cualidad de mito y leyenda que ha llevado a este acontecimiento a erigirse en estandarte inmortal de la personalidad norteamericana. Sin embargo, no lo hizo de forma instantánea, sino que fue el tiempo el que fundió mito e historia en una concepción casi legendaria adaptable al contexto sociopolítico, como símbolo de libertad y patriotismo.

El cine ha sido uno de los medios a través de los cuales El Álamo ha ido entretejiendo su significado con nuestro devenir histórico. Son numerosas las adaptaciones que se han hecho para cine y televisión, entre películas, series y documentales. En todas ellas, la música, que en su momento jugó un rol definitivo, es parte importante. Pero es en las adaptaciones al cine donde se alza como elemento fundamental, sobre todo en los últimos días del asedio. Así, en este artículo estudiamos el tratamiento musical que de los momentos previos y de la batalla dieron los diversos compositores, analizando también el degüello, su importancia en el conjunto de la partitura, sus posibles referentes, su estructura y el carácter del tema. Este estudio se centra en las películas sonoras que tuvieron los hechos de El Álamo como argumento principal o relevante. En conjunto, son seis películas que presentamos en la Tabla 1, 
donde especificamos fecha, productora, director y compositor.

\begin{tabular}{|c|c|c|c|c|}
\hline TÍTULO & ÑO & DIRECTOR & PRODUCTOR & COMPOSITOR \\
\hline Heroes of The Alamo & 1937 & Harry L. Fraser & Anthony J. Xydias & Lee Zahler \\
\hline $\begin{array}{c}\text { Davy Crockett, King of the } \\
\text { wild frontier }\end{array}$ & 1955 & Norman Foster & $\begin{array}{l}\text { Walt Disney } \\
\text { Bill Walsh }\end{array}$ & George Bruns \\
\hline La última orden & 1955 & Frank Lloyd & Herbert Yates & Max Steiner \\
\hline El Álamo & 1960 & John Wayne & $\begin{array}{c}\text { John Wayne } \\
\text { James Edward Grant } \\
\text { Michael Wayne }\end{array}$ & Dimitri Tiomkin \\
\hline $\begin{array}{c}\text { El Álamo, } 13 \text { días para la } \\
\text { gloria }\end{array}$ & 1987 & Burt Kennedy & $\begin{array}{l}\text { Stockton Briggle } \\
\text { Richard Carrothers } \\
\text { Bill Finnegan } \\
\text { Patricia Finnegan } \\
\text { Dennis Hennessy } \\
\text { Sheldon Pinchuk }\end{array}$ & Peter Bernstein \\
\hline El Álamo, la leyenda & 2004 & John Lee Hancock & $\begin{array}{l}\text { Todd Hallowell } \\
\text { K.C. Hodenfield } \\
\text { Ron Howard } \\
\text { Mark Johnson } \\
\text { Philip Steuer } \\
\text { Louisa Velis }\end{array}$ & Carter Burwell \\
\hline
\end{tabular}

TABLA 1: PRESENTA LAS PELÍCULAS SOBRE EL ÁLAMO OBJETO DE ESTUDIO. FUENTE: ELABORACIÓN PROPIA.

Hemos construido una herramienta de análisis de contenido categorial basada en estudios previos ${ }^{1}$. En este caso, construimos tres tablas: una primera en la que analizamos las diferentes versiones del Toque a degüello a través de sus características musicales (fuente, tonalidad, compás, instrumentación, silencio). Y otras dos para el día previo y el día del asalto final, en las cuales analizamos los porcentajes de los diferentes elementos musicales (música, silencio, música diegética e incidental), así como de los diferentes temas que entran en juego en ese determinado momento (tema principal ${ }^{2}$, contratema ${ }^{3}$, otros temas, degüello). Por último señalamos el tema final, entendido en este caso como el último que se escucha en cada uno de los momentos escogidos ${ }^{4}$.

\footnotetext{
${ }^{1}$ El método de análisis seguido en este estudio ha sido comprobado válido para el análisis de la música de cine en varios estudios anteriores como Justo Estebaranz y Pérez García, 2015: 159-166; o Pérez García y Justo Estebaranz, 2016: 9-19. Así mismo, ha sido la herramienta fundamental empleada en la Tesis Doctoral de Pérez García, 2017.

${ }^{2}$ No nos referimos al tema que se alza como principal en los dos momentos escogidos (ya que en ocasiones el más importante durante las batallas no es el tema principal utilizado en el resto de la película), sino al tema principal en su actuación en dichas circunstancias.

${ }^{3}$ Según Conrado Xalabarder (2006: 56 y 2013: 94-100), el contratema es un tema central que contradice a otro tema central, siendo su principal finalidad trasladar a la música el conflicto que se desarrolla en el argumento y magnificarlo. En este caso sí hemos considerado como contratema aquel que se opone al tema principal en los dos momentos escogidos. Normalmente (aunque sea en forma de fragmentos) coincide con el contratema general de la película, pero en otras se limita a los fragmentos de la música de la batalla que no corresponden al tema principal, centrales positivos o al degüello, y que se presentan con connotaciones negativas para los texanos.

${ }^{4}$ El tema final como tal es en realidad el que se escucha en los créditos finales (Xalabarder, 2006: 54 y 2013:108).
} 
Con anterioridad a nosotros, algunos investigadores han tratado sobre las adaptaciones al cine de los sucesos de El Álamo. Niemi se acerca desde una perspectiva histórica, exponiendo en primer lugar los hechos de forma sucinta, y a continuación analizando el tratamiento que se da en las distintas películas que abordaron el tema (Niemi, 2006: 9-16). El autor elige una muestra significativa, pero no estudia la música. Asimismo, en su monografía The Alamo: A Cultural History, Thompson dedica un capítulo a las adaptaciones cinematográficas (Thompson, 2001). Por su parte, Flores (2010) destina un capítulo de su monografía sobre El Álamo a las imágenes cinematográficas, centrándose en tres grandes apartados: fronteras, nacionalismo y la cuestión mexicana. En este libro mencionaba, muy de pasada, algún elemento musical, pero no constituye el foco de su interés. Además de ellos, Graham (1985-1986: 35-66), en su artículo para The Southwest Historical Quarterly, analiza las diferentes adaptaciones, tanto cinematográficas como literarias, dentro de la cultura popular. Un estudio monográfico sobre la música de El Álamo es el que en 2009 publicaron Chemerka y Wiener, analizando los hechos vinculados a la batalla desde el punto de vista musical, en su libro The Music of the Alamo: From 19th Century Ballads to Big-Screen Soundtracks, donde además dedican un capítulo al cine y la televisión (Chemerka y Wiener, 2009).

\section{EL ÁLAMO EN EL CINE (1911-2004)}

Este hecho, hito de la historia norteamericana, se convirtió en símbolo de libertad y patriotismo. Según Niemi (2006: 9), la defensa de El Álamo contra las tropas de Santa Anna es el acontecimiento mítico central en la historia de Texas y, por extensión, un mito central americano. Además, ponía de relieve notables valores y daba relevancia al colono de origen inglés, que aparecía como la víctima inocente. Sin embargo, como ya hemos comentado, su reconocimiento no sería instantáneo, sino que sería el tiempo el que le fuera dando su lugar dentro del contexto sociopolítico.

$\mathrm{Su}$ desarrollo dentro de esta mecánica puede seguirse en el arte, muy especialmente en el cine. Las primeras adaptaciones tuvieron lugar durante la etapa silente: The Immortal Alamo (William F. Haddock, 1911, desaparecida), Martyrs of the Alamo (Christy Cabanne, 1915, reestrenada en 1921 como The Birth of Texas) (Graham, 1985-1986: 46; Niemi, 2006: 9) ${ }^{5}$, y Davy Crockett at the Fall of the Alamo y (Robert N. Bradbury, 1926, perdida en su mayor parte). El tono racista de estas películas encontraba su paralelo en la situación que se vivía en Texas, donde el desarrollo estaba desplazando social y políticamente a los mexicanos (Matovina, 2002: 49). La siguiente adaptación, Heroes of the Alamo (Harry L. Fraser, 1937, con producción de Anthony Xydias, reestrenada por Columbia al año siguiente) ${ }^{6}$, conmemoraba el centenario de la

\footnotetext{
${ }^{5}$ El acompañamiento musical de esta película fue publicado por G. Shirmer, con arreglos de Joseph Carl Breil, y se conserva en la colección de la división musical de la Library of Congress (Chemerka y Wiener, 2009: 113).

${ }^{6}$ Según Niemi (2006: 10), la película era un levantador de la moral patriótica en la era de la Depresión. El director musical fue Lee Zahler. Aunque la idea original era hacer coincidir el estreno de esta película con el centenario de la batalla, la película se estrenaría en septiembre de 1937 (Flores, 2010: 110).
} 
independencia de Texas con gran espíritu patriótico ${ }^{7}$.

Pero sería en los años cincuenta, en plena Guerra Fría, cuando El Álamo alcanzara realmente la categoría de mito a seguir. El país llamaba a la unión, a la libertad y a la valentía ante el miedo al enemigo, y lo hacía a través de su pasado, y este a su vez a través del cine. Tres fueron las películas que trataron el tema directamente, las tres producciones ambiciosas (Graham, 1985-1986: 49). Davy Crockett, rey de la frontera fue una película producida por Bill Walsh y dirigida por Norman Foster en 1955, con guion de Tom Blackburn (Österberg, 2009: 97). La película fue realizada para la TV en Frontierland, como parte de la serie de Walt Disney Disneyland. El último de los tres episodios que constituye el material del film es Davy Crockett at The Alamo, en el que se mostraba el ataque de las tropas mexicanas y la muerte de los defensores del fuerte. Este episodio fue estrenado el 23 de febrero de 1955 (Rowan, 2015: 49). Exhibida primero en TV, se unieron los tres episodios de que constaba, y se estrenaron como un largometraje en salas de cine (concretamente, el 25 de mayo de 1955: Rowan, 2015: 49). Al éxito de la película contribuyó la canción "The Ballad of Davy Crockett", que estuvo en las listas de éxitos casi medio año, desde el 26 de febrero al 9 de julio de 1955 (Chemerka y Wiener, 2009: $89^{8}$ ), manteniéndose en el número uno en el Hit-Parade durante trece semanas (Österberg, 2009: 98).

Por su parte, La última orden (Frank Lloyd, 1955), contada desde la perspectiva de Jim Bowie, contribuía a ello a través de un casting encabezado por Sterling Hayden, para quien esta película era una forma de redención tras su pasado comunista ${ }^{9}$. Se trata de uno de los varios westerns dirigidos por el artesano escocés establecido en Hollywood Frank Lloyd (1888-1960) ${ }^{10}$. Es un honesto relato histórico del sitio del Álamo, aunque en el material publicitario, y en relación al argumento de la película, el director Frank Lloyd decía que el uso de ficción en la realización de películas basadas en la realidad era permisible y con frecuencia dramáticamente deseable siempre que la ficción no contradijese los hechos (Gevinson, 1997: 568).

La producción de este filme enlaza con las otras adaptaciones de la época, conformando una red interesante en cuanto al contexto del mito. Desde 1945, John Wayne había mostrado gran interés en realizar una película sobre El Álamo (McGivern, 2007: 318), y le propuso a Herbert Yates, productor de Republic Pictures, llevarla a cabo en 1951. Debido a que no quería asumir riesgos, el proyecto fue rechazado. Pero tras el éxito de la película de Disney, y quizás queriendo castigar a Wayne por abandonar Republic Pictures tras 15 años, Yates produjo su propia versión, dirigida por Lloyd (Niemi, 2006: 10). Esta película, tal vez por la moda pasajera de Crockett, pudo compensar gastos en

\footnotetext{
${ }^{7}$ La introducción rezaba: "No hay capítulo más heroico en la historia de América que el galante martirio de los 183 americanos masacrados dentro de El Álamo, la antigua misión franciscana de San Antonio (luego conocido como Bexar), en Texas, el 6 de marzo de 1836. Su valiente lucha contra la tiranía y la opresión vio nacer al estado de Texas. Esta película está dedicada respetuosamente a la memoria de aquellos inmortales texanos".

${ }^{8}$ Como dato curioso, en Regreso al futuro (Robert Zemeckis, 1985) se puede escuchar la canción en una jukebox, durante una escena transcurrida el 5 de noviembre de 1955.

9 Perteneciente a los Hollywood Ten, poco antes de esta película había testificado ante el Comité de Actividades Antiamericanas, delatando a algunos de sus compañeros comunistas (McEnteer, 2004: 94).

${ }^{10}$ Langman, 2000: 141. Las escenas de acción, entre ellas el ataque al fuerte, fueron dirigidas por William Witney (Tavernier y Coursodon, 2010: 1208).
} 
taquilla.

Por último, la más recordada y ambiciosa de todas, El Álamo (John Wayne 1960), cuya campaña de publicidad fue "masiva, patriótica y políticamente consciente" (McGivern, 2007: 335). El mismo Wayne afirmaba: "Esta película es América. Espero que ver la batalla de El Álamo recuerde a los americanos que la libertad no es barata. Esta película... bueno... creo que hacerla me ha hecho sentirme útil a mi país. Creo que es importante que los países extranjeros conozcan esta faceta de la lucha americana por la libertad" (citado por McGivern, 2007: 321). A pesar del contratiempo que pudo suponer para Wayne que Yates estrenara una película sobre su idea rechazada, el actor consiguió alcanzar un acuerdo con United Artists en 1956, aunque viéndose obligado a poner dinero de su bolsillo, así como de magnates del petróleo tejanos (Niemi, 2006: 11 y McGivern, 2007: 324-325). A pesar de las expectativas y los problemas de producción y postproducción ${ }^{11}$, la película recuperó inicialmente en taquilla la décima parte de su coste. A ello pudo contribuir que, siendo concebida en la época del "Terror Rojo", Wayne tardó una década en rodarla y estrenarla (Niemi, 2006: 13).

Por tanto, comprobamos cómo el mismo tema de El Álamo trata de inquietudes ligadas a diferentes momentos históricos. Así, según Flores, Heroes of The Alamo habla de las preocupaciones de la era de la Depresión; The Man from The Alamo, del Maccarthysmo; Davy Crockett, rey de la frontera, de la desilusión post-II Guerra Mundial; y The Last Command, de un estado militar-industrial (Flores, 2010: 110).

La guerra de Vietnam trajo consigo la parodia Viva Max (Jerry Paris, 1969), hija de la opinión extendida sobre el conflicto ${ }^{12}$. Concebida como una sátira del nacionalismo y militarismo en la que un general mexicano quiere recuperar El Álamo, esta película lleva música de Ralph Dino, Hugo Montenegro y John Sembello. En 1987 llegaría Álamo: trece días para la gloria (Burt Kennedy, con música de Peter Bernstein ${ }^{13}$ ), una pobre versión para cuyas batallas se acudió al metraje de The Last Command. Por último, la más reciente adaptación cinematográfica (El Álamo: la leyenda, John Lee Hancock, 2004), capturaba el sentimiento patriótico resurgido tras los atentados del 11-S (Niemi, 2006: 14). Esta película, visualmente impactante, es más precisa históricamente. Sin embargo, tan solo consiguió recuperar una cuarta parte de su coste.

\footnotetext{
${ }^{11}$ Clark y Andersen, 1995. Los autores exponen todos los problemas que surgieron durante la realización de la película. A partir de la página 77 hablan de los problemas de preproducción.

${ }^{12}$ Una opinión que refleja perfectamente una de las editoriales del New York Times de 1968: "Si los americanos deben recordar El Álamo, recordemos que hombres valientes murieron innecesariamente en aquella vieja misión y que su sacrificio llevó finalmente a una guerra que aportó muy poco a los Estados Unidos. Perseverar en la locura no es una virtud. Atreverse a aprender de los errores puede ser la más alta forma de coraje". Citado por McEnteer, 2004: 131.

${ }^{13}$ Nacido en 1951, es hijo del gran compositor Elmer Bernstein, de quien tiene influencias en sus partituras para cine. Ha desarrollado la mayor parte de su carrera en televisión. Véase http://www.imdb.com/name/nm0003367/bio?ref_nm_ov_bio_sm http://www.mundobso.com/compositor/bernstein-peter (Consultadas el 11/08/2017). En la música compuesta para la batalla de El Álamo se pueden apreciar las influencias de su padre, como también lo harán en otros títulos ambientados en los EE.UU. del siglo XIX tales como Rough Riders (John Milius, 1997).
} 


\section{LA MÚSICA DEL díA PREVIO A LA BATALla}

A las diez de la noche del día 5 de marzo de 1836 cesaron los disparos ${ }^{14}$. Una inquietante tranquilidad lo inundó todo. Los texanos, en alerta constante durante doce días, pudieron bajar la guardia, las armas siempre al alcance de la mano ${ }^{15}$. Este momento es representado en el cine de diversas maneras, pero siempre con gran respeto, dignidad y patriotismo, dentro de una atmósfera tensa y ciertamente desasosegante, teniendo la música un papel principal.

Varias de las adaptaciones otorgan a Davy Crockett un protagonismo especial debido a la relación del personaje con la música ${ }^{16}$. Su música daba ánimos a unos hombres en continua lucha y fatal destino. Animaba al valor, pero también a la alegría, a través de concursos musicales contra la gaita del sargento escocés John McGregor (Hansen, 2003: 59-60; Hatch, 1999: 77 y 125; Edmonson, 2000: 331) ${ }^{17}$.

No existen testimonios acerca de si Crockett tocó el violín la noche antes del ataque, pero la ocasión, con tal amenaza por delante, era digna de arengas al estilo del de Tennessee. Así lo vieron algunas de las versiones para el cine, como son Heroes of The Alamo y El Álamo: la leyenda, dos películas que llamaban especialmente a la unión en un momento determinado de la historia.

En Heroes of The Alamo se da una curiosa descontextualización temporal al poner en boca de los texanos la canción "The Yellow Rose of Texas", producto del mito creado en la persona de Emily West durante la posterior batalla de San Jacinto. Así, los defensores de El Álamo cantan a coro la canción mientras están sentados ante la fogata (Flores, 2010: 111) ${ }^{18}$. Son el significado y el arraigo de la canción en el corazón de los texanos a los que iba dirigido el film lo que justifica su inclusión. Los espectadores pueden sentir la cercanía y conexión con aquellos hombres cien años después de su

\footnotetext{
${ }^{14}$ A partir del día 3 de marzo, todos los testimonios que se conservan pertenecen a los mexicanos y a los supervivientes. La última carta del coronel Travis data del mismo 3 de marzo, estando dirigida al presidente de la Convención de 1836 (Williams, 1933: 31).

${ }^{15}$ Hemos considerado el día previo desde este mismo instante, es decir, desde que la tranquilidad se apodera de El Álamo hasta los instantes previos al amanecer del día 6.

${ }^{16}$ Es muy interesante la descripción que hace de Crockett una de las supervivientes, Andrea Castañón Villanueva: "Los americanos le dieron una cálida bienvenida. Hicieron fogatas en las calles y el coronel Crockett debió haber dado un gran discurso, porque nunca escuché tanto entusiasmo y hurras en toda mi vida. Cenaron en mi hotel y hubo muchas canciones, historias y algo de bebida. Crockett tocó el violín y lo hizo bien" (Matovina, 2002: 60).

${ }^{17}$ Este personaje tan solo aparece en la versión del 2004, donde además la gaita es parte fundamental de la música. John Lee Hancock comentaba: "Hablé mucho con Carter Burwell sobre la música original y ambos estábamos de acuerdo en que era primordial tener un sentimiento real escocés en ella, porque los escoceses estaban jugando un rol principal de la construcción de América, y por supuesto de Texas". Véase How Scottish piper stole the show at The Alamo. The Scotsman, Scotland's National Newspaper, April 11, 2004, http://www.scotsman.com/news/how-scottish-piper-stole-the-show-at-the-alamo-1-1392378 (Consultada el 25/07/2017).

${ }^{18}$ La canción está en Do Mayor. En este momento se produce una falsa diégesis, pues vemos al grupo de texanos escuchando cómo uno de ellos canta, mientras otro toca la armónica, aunque estamos escuchando la flauta doblando la melodía de la canción una octava alta, mientras es acompañada por unos tenues acordes de guitarra. Después se une al solista todo el grupo, entonando otra estrofa al unísono. A la izquierda vemos a Crockett, que lleva el ritmo con el arco del violín, aunque no lo toca.
} 
muerte. El objetivo, transmitir sentimiento de unión, patriotismo y lucha por la libertad, queda resumido en este enlace temporal a través de la música.

No es Crockett, sin embargo, el que toca la canción con su violín, sino las voces a coro de todos los hombres que defienden el fuerte. El violín aparece inactivo pero dentro de plano, pues los texanos no tardarán en pedir una de las famosas interpretaciones de Crockett. "No más música chicos, es mejor que durmamos". El alegre y dicharachero coronel sabe perfectamente cuándo llega la hora del deber. La alegría, ante la que los soldados mexicanos reaccionaban con incredulidad -"Muy extraño. Hacen música la última noche de sus vidas"-, ha hecho su efecto. Lo que podría parecer música anempática ${ }^{19}$ es en realidad una llamada de atención a la actitud positiva ante la lucha por los ideales americanos. No hay silencio posterior, sino un fragmento de música incidental que da paso a la cartela del día siguiente. Todos afrontan positivamente el momento final de sus vidas como si no fuera tal. No hay tristeza, sino regocijo ante un mito que cumple su centenario como leyenda viva de América.

La versión de John Lee Hancock difiere de todas las anteriores en cuanto al uso del degüello. Es la única versión en la que los mexicanos lo tocan tres veces, y la única en la que el toque final se adelanta una jornada. Carter Burwell, por petición del director, recurre a la partitura original ${ }^{20}$, a la cual contrapone el violín de Crockett en una especie de falsa diégesis, cuyo sonido se levanta muy por encima de la banda del enemigo ${ }^{21}$. De esta forma, el compositor consigue dar la vuelta al significado de la música, convirtiendo el degüello en un arma de intimidación texana frente a la barbarie mexicana, musical y simbólicamente hablando ${ }^{22}$. En primer lugar, por la oposición entre una marcha militar y una elegante melodía de violín que se impone a ella con fuerza. En segundo lugar, por el efecto producido, la paz, aunque solo sea por una noche. "Es impresionante lo que puede conseguir una armonía", dice un sorprendido Crockett al ver el resultado de su intervención. En tercer lugar, por su aparición por separado en diferentes momentos, haciendo alusión a mexicanos y texanos respectivamente. Y finalmente, por la reaparición del "Degüello de Crockett" como tema final de carácter metadiegético, tocado por el espíritu del héroe en señal de victoria tras la batalla de San Jacinto.

La solución adoptada por Burwell es muy ingeniosa. Sobre el toque marcial del ejército de Santa Anna (transportada a la tonalidad de La b Mayor), Crockett eleva una melodía de violín (en la misma tonalidad). Cuando la cámara enfoca a Crockett, el volumen del violín salta al primer plano, y cuando se enfoca al ejército, suena más fuerte el toque de degüello. Uno y otro están en modo mayor, como el de Santa Anna. Cuando terminan, hay un silencio muy significativo, que se rompe por el crepitar de las llamas, y eso da paso a la música de cuerda incidental. La mirada socarrona de Crockett tiene también su correlación con la música, al contraponer su tema al marcial, y conseguir algo

\footnotetext{
${ }^{19}$ Es decir, la que produce un efecto contrario al propuesto por las imágenes (Xalabarder, 2013: 43).

${ }^{20}$ University of Southern California (en Adelante, USC), Warner Bros Archive, Rio Bravo, Box 2, f. 1057.

21 "Quería que Davy Crockett, quien tocaba el violín en escenas anteriores, fuera oído más allá de la estridente pieza militar y encontrar una belleza inherente en la música”. Véase Hancock, J. L. The Alamo. CarterBurwell.com, http://www.carterburwell.com/projects/Alamo.shtml (Consultada el 25/07/2017).

${ }^{22}$ El neoyorkino Carter Burwell (1955) tiene diversas influencias, desde Bernard Herrmann hasta John Coltrane, incluyendo instrumentación étnica. Basa su música en la desintegración de elementos armónicos para crear melodías que mezclan jazz minimalista y orquesta sinfónica, con un predominio de las secciones de cuerda y viento (Carmona, 2008: 87; Carmona, 2012: 50).
} 
unitario. Según Groneman, esta melodía apacigua tanto a los combatientes mexicanos como a los texanos y, bajo la superficie, la escena en la que se inserta sirve como mensaje antibelicista, señalando cómo a través de la música (que comparten unos y otros) se muestra que los contendientes tienen pocas diferencias (Groneman, 2007).

La decisión de incluir a Crockett en ese preciso momento es arriesgada, en cuanto a que no existen documentos que acrediten dicha actuación. Pero fue el carácter del personaje el que hizo a Hancock tomar la decisión. Una decisión que, si bien resta veracidad histórica a la película, aporta una belleza incuestionable. El director comentaba: "Carter redujo cada emoción de la película, todo lo que estábamos tratando de decir, en un lamento precioso, agridulce e increíblemente emotivo. Tal es el poder de la música. Tal es el talento de Carter Burwell'"23. Y tal es el resultado de una pieza musical que alcanza sobradamente su objetivo: una llamada a enfrentar el miedo que, tras el 11-S (2001), se había apoderado de los americanos. Una llamada a luchar a través de armas tan pacíficas como el diálogo musical. Pues no es el horror, sino la belleza, la mejor forma de alcanzar la victoria. Y así lo demuestra Crockett, cuya valiente acción se hace digna de admirar hasta por el enemigo, al que incluso arranca una sonrisa.

La tranquilidad que impone el violín de Crockett se rellena con una variación del tema principal que comienza de forma enfática, señalando la victoria moral que acaban de conseguir, para continuar suavemente con el piano. Los texanos escriben sus últimas cartas. Muestran sus sentimientos más profundos. Dedican los últimos momentos a todo aquello que dejan atrás, a todo aquello a lo que hacía alusión "The Green Leaves of Summer" en la versión de Wayne (1960), pero sin la penetrante melancolía de este tema compuesto por Dimitri Tiomkin ${ }^{24}$.

La versión de Disney, Davy Crockett, King of the Wild Frontier, también otorga el protagonismo principal del día previo a su protagonista, que canta una canción de despedida, "Farewell", a la que se une el resto de los hombres. Sin embargo, no es un violín lo que toca, sino una guitarra. La canción recuerda a "The Green Leaves of Summer" en su carácter melancólico y de despedida ${ }^{25}$, alejándose de aquella en su tono más patriótico y su sentido del deber ${ }^{26}$. El hecho de estar dirigida al público infantil hace que esta última parte sea la que se imponga. Hay tristeza, sí, pero siempre con el orgullo y la alegría de estar luchado juntos por la tierra que se ama. Un aspecto, este, que en la versión de 1960 será completado por otros temas.

En la Tabla 2 presentamos los datos relativos al análisis musical del fragmento correspondiente a la víspera de la batalla en las películas, a fin de clarificar la comparación entre las composiciones del conjunto de las películas estudiadas.

\footnotetext{
${ }^{23}$ Hancock, J. L. The Alamo. CarterBurwell.com, http://www.carterburwell.com/projects/Alamo.shtml (Consultada el 23/07/2017).

${ }^{24}$ Según Chemerka y Wiener (2009: 118), "mientras que la música de 1960 de Tiomkin es de naturaleza melódica, la de Burwell es una representación mucho más auténtica del tipo de música tocada en la década de 1830. Burwell efectivamente utiliza flautas étnicas, violines, cornetas, pífanos, mandolinas, guitarrones y una orquesta de 16 percusionistas".

25 "The home I forsake where my offspring grows/ The grave I forsake where my children reborn/ The home I redeem from the savage and wild/ The home I have loved as a father, his child".

26 "Farewell to my country, I've fought for thee well/ When the savage rushed forth like the demons from hell/ In peace or in war, I have stood by thy side/ My country for thee, I have lived, would have died".
} 


\begin{tabular}{|c|c|c|c|c|c|}
\hline TÍTULO & $\begin{array}{l}\text { Heroes of The } \\
\text { Alamo (1937) }\end{array}$ & $\begin{array}{c}\text { La última orden } \\
\text { (1955) }\end{array}$ & $\begin{array}{c}\text { Davy Crockett, King of } \\
\text { the Wild Frontier } \\
\text { (1955) }\end{array}$ & El Álamo (1960) & $\begin{array}{l}\text { El Álamo: } \\
\text { la leyenda } \\
\text { (2004) }\end{array}$ \\
\hline TOTAL & 200 sg & $385 \mathrm{sg}$ & $56 \mathrm{sg}$ & $385 \mathrm{sg}$ & $490 \mathrm{sg}$ \\
\hline SILENCIO & $17.00 \%$ & $40.78 \%$ & $51 \%$ & $26.23 \%$ & $22.45 \%$ \\
\hline MÚSICA & $83.00 \%$ & $59.22 \%$ & $96.49 \%$ & $73.77 \%$ & $77.55 \%$ \\
\hline DIEGÉTICA & $100.00 \%$ & - & $73.57 \%$ & - & $30.26 \%$ \\
\hline INCIDENTAL & - & $100 \%$ & $26.43 \%$ & $100 \%$ & $69.64 \%$ \\
\hline T. PRINCIPAL & - & $22.29 \%$ & - & $\begin{array}{c}\text { The Green Leaves } \\
\text { of Summer } \\
50.35 \%\end{array}$ & $51.58 \%$ \\
\hline CONTRATEMA & - & - & - & - & - \\
\hline OTROS & $\begin{array}{c}\text { The Yellow Rose } \\
\text { of Texas } 100 \%\end{array}$ & $\begin{array}{c}\text { Consuelo } \\
43.31 \% \\
\text { Otros } \\
34.39 \%\end{array}$ & $\begin{array}{c}\text { Farewell } \\
73.57 \% \\
\text { Otros } \\
26.43 \%\end{array}$ & $\begin{array}{c}\text { Jethro Freedom } \\
26.06 \%\end{array}$ & - \\
\hline DEGÜELLO & - & - & - & $\mathbf{I}-23.59 \%$ & $\begin{array}{c}\text { Santa } \\
\text { Anna } \\
\text { D-28.25\% } \\
\text { Crockett } \\
\text { D-14.21\% }\end{array}$ \\
\hline TEMA FINAL & $\begin{array}{c}\text { The Yellow Rose } \\
\text { of Texas }\end{array}$ & Consuelo & Farewell & Degüello & $\begin{array}{c}\text { Tema } \\
\text { principal }\end{array}$ \\
\hline
\end{tabular}

TABLA 2: ANÁLISIS DE LA MÚSICA DEL DÍA PREVIO A LA BATALLA, EL 5 DE MARZO DE 1836. EN NEGRITA SE SEÑALAN LOS TÍTULOS DE LOS TEMAS. LA I INDICA MÚSICA INCIDENTAL, MIENTRAS QUE LA D INDICA DIÉGESIS. FUENTE: ELABORACIÓN PROPIA.

No hay nada del carisma de Crockett ni de esa fuerte unión en La última orden, donde el punto de vista de Jim Bowie es mucho más grave. El cruce de la línea en silencio bajo una constante lluvia y una carta de Bowie a Jed (Ben Cooper) sobre el futuro de Consuelo (Anna Maria Alberghetti) convierten el último día en una jornada entre lo trágico y lo romántico. Esta última acción de la vida de Bowie incrementa su heroicidad. Enfermo, valiente y con sentimientos: "He gave his love for the love of his land", reza la canción principal. Y es su melodía la que se escucha mientras vemos el contenido de la misiva. No así cuando se la entregue a Jed, momento en el que el motivo de la chica, protagonizado por las cuerdas y el arpa, toma el relevo. Última esperanza de Bowie, futura esperanza de Texas, motivo para luchar por la libertad. Una lucha que se intuye mortal, pero más épica que nunca, cuando Bowie cae al suelo entre horribles gestos de dolor y la entrada de la orquesta al completo.

La melancolía es la emoción principal que transmite la versión de El Álamo de John Wayne. En esta versión, Crockett es un personaje de discursos solemnes, pero rodeado de la alegría y el jolgorio de sus compañeros. No lleva violín, sino que son Beekeeper (Chill Wills) y Smitty (Frankie Avalon) los que cantan y tocan la guitarra, aunque no en los momentos clave, donde son la seriedad y la trascendencia de las palabras pronunciadas anteriormente por el coronel las que mueven la canción “The Green Leaves 
of Summer", protagonista del día previo ${ }^{27}$.

La noche es larga. Eterna. No hay música diegética. Son los acordes de "The Green Leaves of Summer" los que se escuchan de forma incidental mientras los hombres miran al infinito, hacia un pasado que ya no volverá, hacia un futuro que dejarán en herencia, pero que no verán. "No pienso, recuerdo", dice Crockett. La canción canta a los recuerdos y al hogar, a los buenos momentos que se evaporan. No es triste, es la traducción de los sentimientos de unos héroes prestos a sacrificarse por los suyos. Heroica a su manera, a la manera del adiós de las leyendas. El mismo tema acompaña la despedida de Susan (Joan O'Brien) y el Capitán Dickinson (Ken Curtis), una familia que quedará unida para siempre en el recuerdo, en la valentía y en su hija Lisa (Aissa Wayne) ${ }^{28}$. Pero todo cambia cuando, en una última escena antes del día elegido, Bowie (Richard Widmark) concede la libertad a su esclavo, quien se une a la lucha por una libertad aún mayor. El tema que veníamos escuchando parece agonizar en un último y extenso acorde mantenido. No hay piedad ni en la música. El degüello adelanta lo ya sabido. Habrá libertad, sí, pero a costa de la muerte.

Vemos, pues, cómo la música del día previo se caracteriza por varios aspectos simbólicos. En primer lugar, las canciones corales como motivo de unión, siendo la diégesis la presentación predominante al acercar la experiencia al espectador, que puede unir su voz a la de los texanos. En el caso de la versión de 2004 (El Álamo: La leyenda), donde se opta por una variación instrumental e incidental del tema principal, la unión viene dada por el mismo significado del tema desde el inicio. En segundo lugar, el recuerdo de lo dejado atrás, donde las mujeres se alzan como objeto principal de la melancolía masculina. Su lucha desde la barrera será vista también como motivo de valentía. Así mismo, estas serán contempladas como promesa de futuro. El papel de la mujer será tratado de forma enfática en La última orden (1955), donde el motivo de Consuelo se adueñará de la música, culminando la jornada con una trágica aparición en tonalidad menor. Esto da ocasión a hablar del tema final, cuyo carácter sellará el tono con el que se afronta la batalla final. Marcado por la melancolía en tres de las versiones ( $L a$ última orden, Davy Crockett, King of the Wild Frontier y El Álamo), destaca el patriotismo y la unión de las otras dos, si bien la de John Lee Hancock inserta cierto toque melancólico en la variación de cuerdas y piano del tema principal. Por último, el degüello, cuya presencia será fundamental el día de la batalla, aparece aquí en dos ocasiones: como tema final en El Álamo (1960), y como tema fundamental de carácter especial en El Álamo: La leyenda (2004). Tan fundamental que sentará las bases del resto de la música de la película y su consecuente significado para con esta.

\footnotetext{
${ }^{27}$ En este sentido, Dimitri Tiomkin contaba: "Necesitábamos una canción para justo antes de la incursión final, con la que la audiencia supiera, y todos nosotros supiéramos, que los defensores iban a morir [...] Duke Wayne dijo, 'Necesitamos una canción seria, una canción que diga que es tiempo de morir, tiempo de irse"" (citado por Karlin, 1994: 201-202).

28 "Twas so good to be young then/ To be close to the earth/ And to stand by your wife/ At the moment of birth".
} 


\section{LA MÚSICA DEL DÍA DE LA BATALLA: DEL DEGÜELLO AL ASALTO FINAL}

El asalto final tuvo lugar la madrugada del 6 de marzo de $1836^{29}$. A las cuatro de la mañana, las tropas de San Anna se presentaron frente a la antigua misión. Su objetivo era acabar con los traidores atacando la construcción por sus cuatro frentes a la vez. No habría piedad para con nadie, ni siquiera para todos los mexicanos caídos en un ataque sin control ${ }^{30}$. Para ellos la opción no era victoria o muerte, sino ambas cosas a la vez.

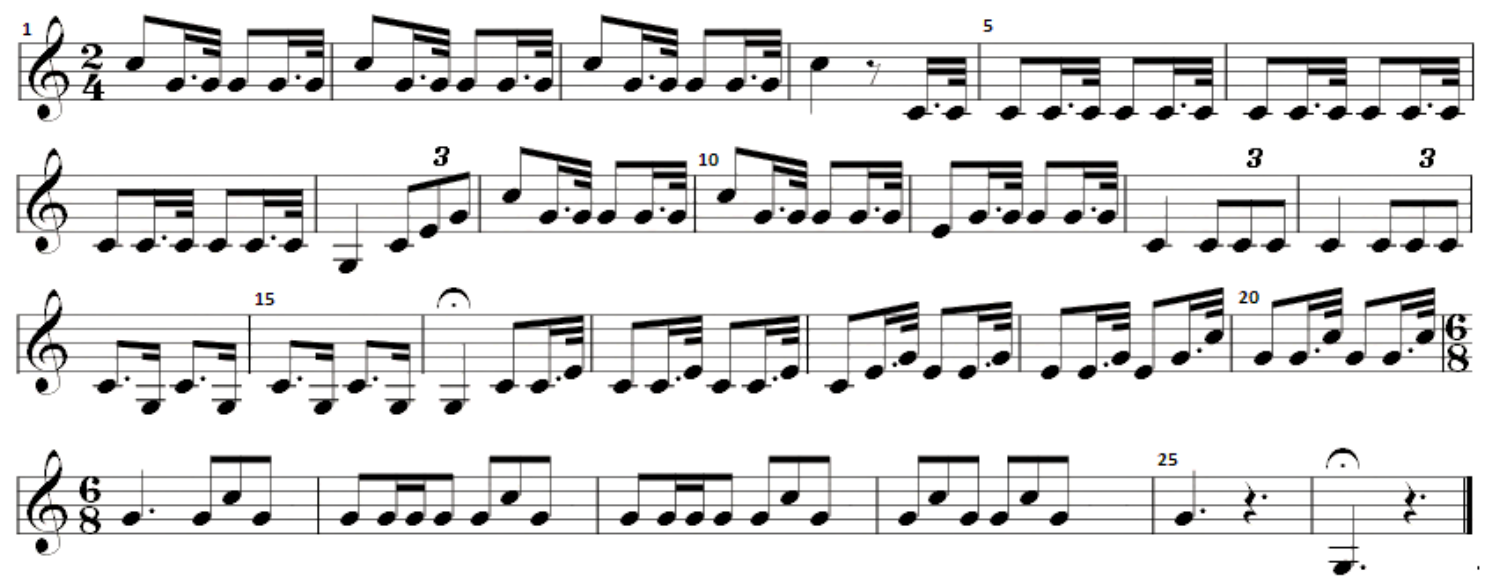

FIGURA 1: PARTITURA DEL TOQUE A DEGÜELLO DE SANTA ANNA. FUENTE: TRANSCRIPCIÓN PROPIA A PARTIR DE UNA REPRODUCCIÓN DEL ORIGINAL CONSERVADA EN EL WARNER BROS. ARCHIVE ${ }^{31}$.

La muerte sin piedad, motivo de arenga para unos y de intimidación para otros, vendrá marcada por el Toque a degüello ${ }^{32}$, cuya presencia es confirmada por muchos de

\footnotetext{
${ }^{29}$ Para el análisis hemos considerado el día del asalto final desde el cambio de plano que nos sitúa en la mañana del 6 de marzo, hasta el nuevo cambio de situación, en caso de que lo haya. De este modo, una vez que la narración pasa a San Jacinto, ya no ha sido considerado dentro del análisis.

${ }^{30}$ La narración del mexicano Vicente Fisola, uno de los supervivientes, reflejaba muy bien este sentimiento: "Nuestra pérdida fue muy grande [...] el ataque fue extremadamente poco juicioso y en oposición al reglamento militar, ya que nuestros propios hombres fueron expuestos no solo al fuego del enemigo sino también a nuestras propias columnas de atacantes por los otros frentes" (citado por Williams, 1933: 35).

${ }^{31}$ USC, Warner Bros Archive, Rio Bravo, Box 2, f. 1057.

${ }^{32}$ La música como instrumento de amenaza e intimidación es un arma de eficacia probada en otras batallas de cine. Es muy interesante la comparación de este hecho con el del sitio de Baler en las versiones cinematográficas: Los últimos de Filipinas (Antonio Román, 1945) y 1898. Los últimos de Filipinas (Salvador Calvo, 2016). En ellas, los filipinos utilizan la canción original compuesta por Jorge Halpern y letra de Enrique Llovet "Yo te diré", para distraer, desestabilizar y poner nerviosos a los españoles, además de ser una amenaza constante de la cercanía e intenciones del enemigo. Si bien no es un hecho documentado, en cuanto a que los filipinos no utilizaron música para este fin, la canción funciona dentro del contexto de ambas películas, reforzando el concepto de seducción femenina que sí está documentado como arma real del conflicto, así como desestabilizando psicológicamente al débil enemigo sitiado. El carácter anempático de la misma contribuye a aumentar su efecto.
} 
los supervivientes ${ }^{33}$. Entre los muchos toques que contempla el reglamento militar es el degüello uno de los más temidos. Equivalente al alzamiento de la bandera roja, significa sin piedad, sin cuartel. El más famoso de los toques a degüello tuvo lugar en el sitio de El Álamo. Sin embargo, no fueron los texanos los primeros en probar su efectividad. De procedencia oriental (Lafuente Alcántara, 1852: 217), fue adoptado por los españoles, quienes hicieron gran uso de él en el siglo XIX ${ }^{34}$, habiéndolo introducido en América durante la independencia de los virreinato ${ }^{35}$. Por ello existen tres versiones del degüello: la de la banda de Villa, una encontrada por Samuel E. Asbury y la oficial de 1836 (Hansen, 2003: 723). Con diferentes arreglos, todas ellas están escritas en Do Mayor, con un ámbito de onceava, desde Sol una octava más baja a Do.

El toque a degüello es parte esencial de la historia de El Álamo, lo cual se ve reflejado en las diferentes adaptaciones al cine. Entre 1953 y 1960 se contabilizan no menos de cuatro versiones diferentes. Sin embargo, tan solo la versión de 2004 se adecua a los hechos históricos, siendo la única película que utiliza la partitura original, así como la única en la que los mexicanos lo tocan en tres ocasiones. El degüello ha sido, pues, pieza clave en la construcción de la leyenda más allá de la historia. Susceptible de nuevas interpretaciones musicales y simbólicas, cada compositor lo ha convertido en un tema propio, aportando su parte a la construcción del mito.

\begin{tabular}{|c|c|c|c|c|c|c|}
\hline Tí́TULO & DEGÜELLO & FUENTE & TONALIDAD & COMPÁS & INSTRUMENTACIÓN & SILENCIO \\
\hline $\begin{array}{c}\text { Heroes of The } \\
\text { Alamo }\end{array}$ & Lee Zahler & & Si b Mayor & & Corneta & No \\
\hline La última orden & Max Steiner & $\begin{array}{c}\text { Adaptación } \\
\text { Toque de } \\
\text { muerte }\end{array}$ & Fa Mayor & $2 / 4$ & Cornetas, tambores & No \\
\hline $\begin{array}{c}\text { Davy Crockett, King } \\
\text { of the Wild Frontier }\end{array}$ & $\begin{array}{c}\text { Thomas W. } \\
\text { Blackburn }\end{array}$ & & La b Mayor & & Cornetas & No \\
\hline $\begin{array}{c}\text { El } \\
\text { Alamo }\end{array}$ & $\begin{array}{c}\text { Dimitri } \\
\text { Tiomkin }\end{array}$ & $\begin{array}{c}\text { Composición } \\
\text { propia }\end{array}$ & Re menor & $4 / 4$ & Metales, tambores & Sí \\
\hline $\begin{array}{c}\text { El Alamo, trece días } \\
\text { para la gloria }\end{array}$ & Peter Bernstein & Max Steiner & Fa Mayor & $2 / 4$ & Cornetas, tambores & Sí \\
\hline
\end{tabular}

\footnotetext{
${ }^{33}$ Vicente Fisola contaba: "Al sonido de la corneta ellos no podían dudar por más tiempo que la hora de conquistar o morir había llegado" (citado por Williams, 1933: 34).

${ }^{34}$ En el siglo XVIII este toque quedaba contemplado en las ordenanzas militares como "la señal que fixa el momento en que se va a atacar" (Ordenanzas, 1768: 155). Un significado similar se le daba en el siglo XIX: "Toque militar del siglo XVI que servía de señal para lanzarse al enemigo al arma blanca” (J. D. V. M., 1863: 14).

${ }^{35}$ En 1824, el reglamento del ejército mexicano lo contemplaba en varios de sus apartados, haciendo alusión a este como el toque que: "solo se tocará cuando después de haberse movido la tropa para cargar se halle como a ochenta pasos del enemigo, servirá para que al oírlo tome el escape con la decisión y demás reglas que se fijan en las cargas" (Reglamento, 1824).
} 


\begin{tabular}{|c|c|c|c|c|c|c|}
\hline $\begin{array}{c}\text { El Alamo, } \boldsymbol{l a} \\
\text { leyenda }\end{array}$ & Carter Burwell & $\begin{array}{c}\text { Degüello 1836 } \\
+ \\
\text { Composición } \\
\text { propia }\end{array}$ & La b Mayor & $2 / 4$ & $\begin{array}{c}\text { Cornetas, tambores, } \\
\text { flautas } \\
+ \\
\text { Violín }\end{array}$ & Sí \\
\hline
\end{tabular}

TABLA 3: ANÁLISIS DEL TOQUE A DEGÜELLO EN LAS DIFERENTES VERSIONES CINEMATOGRÁFICAS. FUENTE: ELABORACIÓN PROPIA.

Pese a ser el único que utiliza la versión original de Santa Anna (como se puede ver en la Tabla 3), Carter Burwell le añade el toque personal de la armonía, contraponiendo al seco toque militar el precioso "Degüello de Crockett" al violín. Pero esto solo ocurre en la tercera ocasión en la que los mexicanos tocan a degüello. Las dos primeras veces, correspondientes a los días 3 y 4 de marzo, se escucha en solitario, mientras que la tercera lo hace en conjunto con el violín del de Tennessee. Esto dará lugar a dividir el tema en dos variantes dentro de la música incidental. La primera, correspondiente a los mexicanos, será el degüello tal cual, y aparecerá en los momentos más brutales de la batalla, en alusión a la amenaza y crueldad del enemigo. Aunque será un degüello que no encuentra todo su poder intimidatorio, pues los mismos texanos lo encaran con comentarios satíricos la primera vez que lo escuchan: "Han traído una banda, parece que tienen algo que celebrar".

La segunda, por su parte, será símbolo de valentía, honor, patriotismo y heroísmo. Desde su delicadeza, servirá de azote a los mexicanos, de victoria moral ante el enemigo. Así ocurre en los momentos previos a la ejecución de Crockett. Un hombre solo ante un ejército de miles, atado y sin armas, exige la rendición de Santa Anna al son de ese degüello que una vez les hizo callar y hasta ganó la admiración de algunos de ellos. Una suave corneta en solitario toca las patrióticas notas. Victoria o muerte. Honor, valentía y dignidad. La misma melodía, como ya apuntamos, volverá a escucharse de forma metadiegética al final ${ }^{36}$. Es el espíritu americano el que habla, más fuerte que todos los ejércitos.

Aparte del uso del degüello, Carter Burwell aporta otro recurso interesante a este momento del asalto final, el cual bebe directamente de Solo ante el peligro (Fred Zinnemann, 1952). Burwell se inspirará en Tiomkin, tal como hará posteriormente para el tema "River crossing" de Valor de ley (Joel y Ethan Coen, 2010) ${ }^{37}$. En este caso utiliza la misma estrategia que el compositor ucraniano a la llegada del tren que traía a Frank Miller. Los mexicanos se acercan. En El Álamo todos están dormidos menos Crockett. La muerte próxima le impide cerrar los ojos. Violín en mano, empieza a pulsar una cuerda al ritmo de unos segundos tan largos como la espera de la pena de muerte. Cada pulsación coincide con el plano de uno de los texanos: Travis, Bowie... el ejército cada vez está

${ }^{36}$ La música metadiegética es definida por Stilwell (2007: 186): “Cuando esta frontera entre diegético y no diegético es atravesada, siempre hay un significado [...] Un momento estamos en el realismo diegético y, en un abrir y cerrar de ojos, como cruzando el espejo de Alicia, estamos en el mundo no diegético del otro lado". Por su parte, para Gorbman es aquella que funciona como la expresión de la experiencia subjetiva de los personajes (Wierzbicki, 2012: 183).

${ }^{37}$ El mismo compositor reconocía la influencia: "sí, hay un momento Dimitri Tiomkin cuando Mattie cruza el río acompañada por los metales, las cuerdas y los timbales". Véase Burwell, C. True Grit. CarterBurwell.com, http://www.carterburwell.com/projects/True_Grit.shtml (Consultada el 25/07/2017). 
más cerca. El violín deja de sonar. Ya están aquí. No hay un crescendo ni una sirena de tren que concluya el tema dejándonos a la expectativa. No hay un incremento del ritmo ni un motivo musical que nos avise de que el enemigo está cerca. La tensión es menor, pero la intención es la misma y la fuente es clara.

En el caso de La última orden, Steiner compone un degüello totalmente original. Sin embargo, su uso se limita exclusivamente al momento concreto en el que el ejército de Santa Anna se dispone al asalto final. Hasta entonces, lo único que adelanta la terrible conclusión es el toque de muerte que se escucha al final de los créditos iniciales, en el cual está claramente inspirado el personal degüello de Steiner. El sentido de muerte viene implícito en la fuente de inspiración. Es la forma en la que Steiner lo concibe la que transmite el horror fatal y el miedo aterrador. Tras un redoble de tambor que sigue a la orden de degüello gritada por un soldado, tiene lugar el primer toque en $\mathrm{Fa}$, cuyo motivo se irá repitiendo con modificaciones. Así, el segundo está en Sol b, el tercero en La b, empezando a producirse solapamientos de un motivo con otro que dan lugar a disonancias que no estaban presentes la primera vez. Es un recurso apropiado para contribuir a incrementar la sensación de caos -sonoro y visual- propia de la batalla presta a producirse, con la música mezclada con el ruido de escopetas y fusiles. Con ello, el austriaco consigue llevar el toque a un nivel de inquietud que traspasa las barreras del miedo y llama directamente a la fatalidad. Un recurso similar será utilizado por Peter Bernstein en Álamo: trece días para la gloria (1987). En esta versión, no solo se acudió al material visual de La última orden para el asalto final, sino también al material musical. Así, el compositor americano recurrió al modelo de Steiner, presentando el degüello en Fa M, como una variación del motivo aparecido en La última orden, y luego repite tres veces más subiendo de semitono (Sol b, Sol, La b). El compositor ha utilizado incluso el solapamiento de la presentación del motivo en las diferentes tonalidades, tal como había ideado Steiner para contribuir a crear mayor tensión.

El combate está musicado de forma muy clásica, insertándose algún toque militar, así como ciertos fragmentos del motivo de Consuelo y el tema de Jim Bowie, que pone el broche final, con su heroica muerte. Una vez concluida la batalla, los mexicanos tocan a silencio, lo que otorga algo de compasión a un ejército que es retratado con total frialdad. Merece destacarse - por presencia dominante durante la batalla y por interés musical- el tema que ya venía asociado al ejército mexicano en su marcha hacia Texas, y que bebe directamente de "La marcha de los toreros" de la ópera Carmen de Bizet, una elección que no es casual. Aparte de tener un tono épico y triunfal, el público podría asociarla con lo español o lo hispano (en relación al ejército mexicano). Junto a este, será el motivo de Consuelo - que en esta ocasión también hará alusión a Susan Dickinson- el de mayor protagonismo, imponiéndose al tema principal, la canción "Jim Bowie", con letra de Sidney Clare, e interpretada por la estrella del cine musical Gordon MacRae ${ }^{38}$. Esta circunstancia, sin embargo, más que dejar en segundo plano al protagonista, completa su descripción heroica. Bowie pone a la chica y al futuro por encima de su propia persona, la cual quedará recordada -junto con todos los caídos- al final de la película cuando, ya muerto, el joven Jeb se reúna de nuevo con Consuelo. Por otra parte, en algunos momentos se puede rastrear la presencia de Mickey-Mousing en los combates

38 Este tema será el leitmotiv de Jim Bowie durante toda la película. Conviene recordar que Steiner, compositor de influencias wagnerianas, es considerado como el creador de los leitmotivs en el cine (Carmona, 2008: 489-490). 
cuerpo a cuerpo. Una secuencia, por tanto, llena de recursos y detalles interesantes. No por casualidad Padrol considera que el "Asalto final" y la "Marcha del General Santa Anna" son momentos extraordinarios de música descriptiva (Padrol, 2007: 18).

Pero es, sin duda, el "Degüello" de Tiomkin el que ha pasado a la historia, hasta el punto de llegarse a confundir con el toque mismo. Compuesto inicialmente para Río Bravo (Howard Hawks, 1959) -donde el mexicano Burdette (John Russell) lo utilizaba para amenazar al sheriff Chance (John Wayne) y sus hombres- fue en El Alamo donde encontró su total inclusión dentro del mito $^{39}$. Su influencia ha sido abrumadora, sobre todo en el western italiano, donde fue introducido por Ennio Morricone ${ }^{40}$. El compositor italiano lo utilizó como inspiración para los solos de trompeta de la Trilogía del Dólar, dando lugar a una tendencia definida dentro del western europeo (Justo Estebaranz y Pérez García, 2015: 106, 107 y 109). Posteriormente, y de forma aún más clara, en cuanto a que se trata de la melodía original de Tiomkin y lleva por título "Degüello", lo usaría Morricone en Me verás volver (Ettore Maria Fizzarotti, 1966). En esta ocasión de forma diegética y con letra en italiano, cantada por el joven Gianni Morandi -reclamo comercial del filme-, y teniendo como conexión directa con el western un niño disfrazado de vaquero, que es precisamente quien pide la canción ${ }^{41}$.

En todas las ocasiones el tema adquiere un significado funesto. Los solos de trompeta del western europeo anuncian la muerte de uno o más de los combatientes en el duelo final. Duelos a muerte donde no existe la palabra piedad ${ }^{42}$. Por su parte, la versión de Me verás volver (escrita en Si b menor), pese a ser tan solo una excusa sin significado dramático dentro de la narración -lo cual confirma la enorme influencia de Tiomkin sobre el compositor italiano-, habla de la muerte en dos sentidos: el que muere y el que mata ${ }^{43}$, un significado acorde con el que Tiomkin quiso darle al tema en El Álamo.

Aun siendo la versión de Wayne una de las más directamente vinculadas con el clima de tensión existente durante la Guerra Fría, el trato que reciben los mexicanos en ella -pese a ser el enemigo a vencer- es mucho menos discriminatorio que en las anteriores. No en vano, John Wayne era un enamorado de México ${ }^{44}$. Por ello, el degüello

\footnotetext{
${ }^{39}$ El degüello es definido erróneamente por Padrol (2007: 18) como un "himno de los mexicanos a los condenados a muerte".

${ }^{40} \mathrm{Si}$ bien la influencia se dio en mayor medida a través de Río Bravo, sería la tonalidad de Re menor utilizada en El Álamo, en lugar del La menor empleada en la primera, la que marcaría las posteriores tendencias.

${ }^{41}$ Este musicarello, dirigido por un especialista del género, se rodó el mismo año que El bueno, el feo y el malo, en la que se aprecia el uso de los solos de trompeta de influencia tiomkiniana. Por tanto, Morricone conocía muy bien el tema original, que ya había adaptado ese mismo año, y cabe considerar esta película como un eslabón importante en la difusión del tema del Degüello de Tiomkin en Italia.

${ }^{42}$ Este simbolismo ha sido llevado incluso a la Semana Santa, donde la muerte sin piedad es parte central de la Pasión de Cristo. Ejemplo de ello es la marcha "Por un puñado de denarios" que Ignacio Bermúdez compuso para la Semana Santa sevillana del año 2012, en la que había un solo de trompeta inspirado directamente en Por un puñado de dólares. Véase El próximo Lunes Santo se estrenará la marcha "Por un puñado de denarios". Blogs. Cofrades. ABC de Sevilla, http://cofrades.sevilla.abc.es/profiles/blogs/el-prximo-lunes-santo-se-estrenar-la-marcha-por-un-pu-ado-de (Consultada el 26/07/2017).

${ }^{43}$ La última estrofa dice lo siguiente: "La vita di un uomo cosa conta per te/ ricorda, però quando lui cadrà/ che la parte migliore di te/ morirà". Es decir: "La vida de un hombre es importante/ recuerda, no obstante, cuando caiga/ que la mejor parte de ti/ morirá".

${ }^{44}$ Allí conoció a su mujer Pilar, y allí pasaba largas temporadas con sus amigos, así como en diferentes rodajes.
} 
adquiere un sentido algo diferente que se extiende a ambos grupos de combatientes. Al fin y al cabo, la muerte les llegará a unos y a otros tarde o temprano.

Tiomkin comentaba: "no quiero aterrorizar a los defensores. Él (John Wayne) dijo 'lo sé, pero ¿puedes encontrar diferentes formas de utilizarla?'. Yo dije, 'sí', y la usé como un lamento por la muerte y caída de los soldados texanos, la usé como una pieza de música militar justo antes de la batalla y la usé para glorificar la muerte de Crockett" (citado por Munn, 2003: 220). Y así fue, pues el degüello aparece de forma incidental durante toda la película, desde los créditos iniciales hasta el final del asedio, tomando diferentes significados. Como tema inicial alude no solo a la muerte de los texanos, sino a la de todos los hombres que lucharon, pues todos lo hicieron por una tierra que consideraban suya. A partir de entonces, estará relacionado principalmente con la amenaza mexicana, apareciendo en los momentos en los que el miedo o la inseguridad hagan acto de presencia entre los americanos. Durante el asalto final, aparecerá en aquellos momentos en los que los mexicanos tomen ventaja, siendo muy significativo el instante previo a la muerte de Crockett. Finalmente, como un lamento: el degüello exhala su último aliento a la llegada de Smitty. Todo ha terminado.

Pero el momento determinante, como en toda adaptación de la historia, es su aparición diegética previa al asalto final. En esta ocasión, el terror de la amenaza es incrementado por un monumental silencio. No un silencio de paz como el de la versión de John Lee Hancock (2004), sino un silencio de muerte, único entre todas las adaptaciones. La tensión es enorme. El terror llega al límite. Sin el estilo militar de Steiner ni la veracidad y armonía de Burwell, el "Degüello" de Tiomkin consigue no solo sobrecoger, sino también transmitir de alguna forma un sentimiento compartido por ambos bandos. La tonalidad en Re menor le aporta un aire de aflicción del que carecen los toques militares, delatando un fondo de empatía. Sin embargo, no deja de ser efectivo, pues no hay nada más turbador que un asesino de rostro gentil.



FIGURA 2: FRAGMENTO DEL “DEGÜELLO” DE DIMITRI TIOMKIN PARA EL ÁLAMO (1960). FUENTE: TRANSCRIPCIÓN PROPIA ${ }^{45}$.

Las otras dos adaptaciones, Heroes of The Alamo y Davy Crockett, King of the Wild Frontier, son menos interesantes en este sentido, destacando la condición de falsa diégesis. En la primera por motivos de volumen, y en la segunda por inserción en la

${ }^{45}$ En los títulos de crédito iniciales de la película de Wayne suena una versión del degüello más pausada, trasunto de la que apareció en Río Bravo. En cambio, el que se emplea en los momentos previos a la batalla es una versión más enérgica, de acusado carácter militar, apoyada en un ritmo muy marcado a cargo de la percusión. 
música incidental, con la cual se llega a confundir la parte diegética. En esta versión, además, y quizás motivada por la propia productora y el público al que iba dirigida, el asalto queda reducido al mínimo, pasando rápidamente a la conclusión del filme a través de la inserción de un plano de la bandera de 1824 ondeando al son de la canción principal. No podemos olvidar, aunque solo sea como nota de interés, la parodia de 1969 Viva Max, en la que el tema principal es una marcha militar que, si bien tiene un aire pop muy de la época, adquiere connotaciones reminiscentes del degüello en la instrumentación y el carácter militar.

\begin{tabular}{|c|c|c|c|c|c|c|}
\hline TÍTULO & $\begin{array}{c}\text { Heroes of The } \\
\text { Alamo } \\
\text { (1937) }\end{array}$ & $\begin{array}{l}\text { La última } \\
\text { orden } \\
\text { (1955) }\end{array}$ & $\begin{array}{l}\text { Davy Crockett, } \\
\text { King of the Wild } \\
\text { Frontier } \\
\text { (1955) }\end{array}$ & $\begin{array}{l}\text { El Álamo } \\
\text { (1960) }\end{array}$ & $\begin{array}{c}\text { El Álamo, trece } \\
\text { días para la } \\
\text { gloria } \\
(1987)\end{array}$ & $\begin{array}{l}\text { El Álamo, la } \\
\text { leyenda } \\
\text { (2004) }\end{array}$ \\
\hline TOTAL & $531 \mathrm{sg}$ & $563 \mathrm{sg}$ & $257 \mathrm{sg}$ & $997 \mathrm{sg}$ & 710 sg & $1.112 \mathrm{sg}$ \\
\hline SILENCIO & $13.00 \%$ & $6.04 \%$ & - & $4.41 \%$ & $39.01 \%$ & $9.80 \%$ \\
\hline MÚSICA & $87.00 \%$ & $93.96 \%$ & $100 \%$ & $95.59 \%$ & $60.99 \%$ & $90.20 \%$ \\
\hline DIEGÉTICA & $6.06 \%$ & $16.26 \%$ & $17.51 \%$ & $20.15 \%$ & $12.01 \%$ & $8.18 \%$ \\
\hline INCIDENTAL & $93.94 \%$ & $83.74 \%$ & $82.49 \%$ & $79.85 \%$ & $87.99 \%$ & $100 \%$ \\
\hline T. PRINCIPAL & $13.42 \%$ & $2.27 \%$ & $10.51 \%$ & $\begin{array}{c}\text { Temas The } \\
\text { Ballad of The } \\
\text { Alamo/The Eyes } \\
\text { of Texas } \\
13.11 \%\end{array}$ & $27.71 \%$ & $22.43 \%$ \\
\hline CONTRATEMA & $74.03 \%$ & $54.10 \%$ & $62.65 \%$ & $46.17 \%$ & $76.44 \%$ & $64.30 \%$ \\
\hline OTROS & $\begin{array}{l}\text { Susan } \\
6.49 \%\end{array}$ & $\begin{array}{c}\text { Consuelo } \\
23.83 \% \\
\text { Toque final } \\
4.91 \%\end{array}$ & - & $\begin{array}{c}\text { Tennessee Babe } \\
11.33 \%\end{array}$ & - & - \\
\hline DEGÜELLO & D- $6.06 \%$ & D-14.85\% & $\begin{array}{c}26.85 \% \\
\text { D- } 17.51 \% \\
\text { I- } 9.34 \%\end{array}$ & $\begin{array}{c}26.23 \% \\
\text { D-20.15\% } \\
\text { I- } 6.09 \%\end{array}$ & D- $6.93 \%$ & $\begin{array}{c}\text { Santa Anna } \\
\text { I-1.60\% } \\
\text { Crockett } \\
\text { I- } 11.67 \%\end{array}$ \\
\hline TEMA FINAL & Tema principal & $\begin{array}{l}\text { Tema principal } \\
\text { y Toque de } \\
\text { corneta }\end{array}$ & Tema principal & $\begin{array}{c}\text { The Ballad of The } \\
\text { Alamo }\end{array}$ & Tema principal & $\begin{array}{l}\text { Degüello de } \\
\text { Crockett }\end{array}$ \\
\hline
\end{tabular}

TABLA 4: ANÁLISIS DE LA MÚSICA DEL ASALTO FINAL, EL DÍA 6 DE MARZO. EN NEGRITA SE SEÑALAN LOS TÍTULOS DE LOS TEMAS. LA I INDICA MÚSICA INCIDENTAL, MIENTRAS QUE LA D INDICA DIÉGESIS. FUENTE: ELABORACIÓN PROPIA.

Tras el toque a degüello, en las diferentes versiones aparece el asalto final al fuerte, que viene acompañado por un potente fragmento musical que se combina con el sonido diegético. Cornetas y tambores, cañonazos y disparos de fusil y gritos de los contendientes aparecen en pantalla junto con el fragmento orquestal que magnifica la crudeza y la épica del combate. Casi todas las versiones, en las escenas que suceden 
dentro de la iglesia o que muestran la muerte de uno de los héroes texanos, emplean campanas dentro de la música incidental en alusión a la muerte. En la Tabla 4 se presenta el análisis de datos relativo a este fragmento.

En general, todas las adaptaciones optan por la glorificación del patriotismo y heroísmo en el asalto final, lo cual se refleja claramente en la elección del tema final, siendo este el principal o el central más importante para tal fin, como ocurre con "Degüello de Crockett" o "The Ballad of The Alamo"46. En el caso de La última orden, donde el asalto acaba con un toque de corneta inspirado en el Toque de silencio, el tema principal retrasará su aparición hasta la conclusión de la película, cerrando el círculo con la llegada de las mujeres supervivientes al campamento de Houston. Y serán precisamente las mujeres las que impongan su impronta mediante sus temas, símbolo de fuerza, valentía y esperanza. Un significado que queda claramente especificado en la versión de Wayne con el tema "Tennessee Babe" a la salida de Susan y su hija.

Sin embargo, no puede dejarse de lado la fatalidad, con un gran dominio del contratema, cuyos porcentajes, sumados a los del degüello, sobrepasan con creces a los temas de carácter positivo, tanto como el ejército mexicano superaba en número a los sitiados texanos. Un degüello que, como hemos podido comprobar, da mucho juego a los compositores, adquiriendo complejidad e innovación en cada nueva versión, en ninguna de las cuales, salvo en El Álamo, la leyenda, se utiliza la melodía original. Excepto en Heroes of The Alamo, La última orden y El Álamo, trece días para la gloria, lo usan tanto de forma diegética como incidental, siendo el de Burwell el único que adquiere un doble carácter, uno de ellos positivo. Por último, dentro de este apartado de la música negativa cabe destacar el uso del silencio que hace Tiomkin, cuyo carácter terrorífico es mayor incluso que el de la música; lo mismo ocurre tras el "Degüello de Crockett", mediante el que Carter Burwell transmite el efecto de su composición. En el resto de las versiones, el silencio no tiene el mismo valor simbólico, limitándose en la mayor parte de las ocasiones a escenas de batalla donde los ruidos forman la música del momento.

\section{CONCLUSIONES}

La defensa y batalla de El Álamo constituye uno de los episodios fundamentales de la historia de Texas y, por extensión, de Estados Unidos. Desde varios lustros antes de la conmemoración del centenario del suceso en 1936 hubo interés por llevar al cine estos acontecimientos, más o menos mitificados. Entre 1937 y 2004 aparecerán seis versiones americanas, desde Heroes of The Alamo, dirigida por Harry L. Fraser, hasta El Álamo, la leyenda, dirigida por John Lee Hancock.

El tratamiento musical que se dio a los momentos decisivos de El Álamo -el día previo a la batalla y el asalto final- ha variado entre las diferentes versiones llevadas a la gran pantalla. La música desempeñó un papel fundamental en todas ellas, utilizando los compositores diferentes recursos, como hemos podido observar en los datos

\footnotetext{
${ }^{46}$ Esta canción cuenta la historia de El Álamo desde la llegada de los hombres hasta el mismo final. Es interesante la alusión que se hace al degüello en la letra: "Santa Anna turned scarlet/ "Play deguello!" he roared/ "I will show them no quarter/ Everyone will be put to the sword!".
} 
representados en las tablas de este trabajo, obtenidos mediante la herramienta de análisis de contenido categorial que hemos diseñado y aplicado al estudio detallado de estas películas. Entre estos recursos, destacan el empleo de canciones corales como símbolo de unión, el uso de la diégesis para introducir al espectador en la experiencia de los asediados, y la inclusión de temas alusivos a las mujeres como símbolo de esperanza y valentía. A todo ello hay que sumar la visión diferenciada de los temas y motivos musicales en cuestión de orden de aparición, número de repeticiones y porcentaje total de presencia de cada elemento en las diferentes versiones cinematográficas, relacionados con el tono de cada película.

Hemos identificado el uso del toque de degüello como momento capital del episodio narrado en estas películas. Si bien se conocía el material musical original presente en la batalla -el toque de degüello del ejército de Santa Anna, que utilizó Burwell en la película dirigida por John Lee Hancock por expreso deseo del director-, no siempre se empleó. De hecho, en el resto de películas se optó por otros toques de inspiración militar, o incluso por otros fragmentos musicales originales de una libertad y dramatismo mayores, con el fin de proporcionar el carácter más adecuado al tono de cada película. Hemos analizado el degüello, atendiendo a los siguientes aspectos: fuente, tonalidad, compás, instrumentación y uso del silencio. También hemos podido identificar los posibles referentes que tuvieron a la vista los compositores, así como su estructura y el carácter del tema. Entre todas las versiones, destaca la de Tiomkin, quien prefirió emplear una pieza de su autoría para el degüello a pesar de tener a mano la partitura del toque mexicano. El degüello que incluye en El Álamo lo había escrito originalmente para Río Bravo, un año antes de la película dirigida por Wayne, y aquí lo desarrollaría con diferentes variantes, de las que nos ha interesado especialmente aquella que suena en los momentos previos a la batalla. El degüello de Tiomkin, y no el original, sería desde entonces el referente máximo de los duelos en el western italiano, como acreditan las partituras de Ennio Morricone para la Trilogía del Dólar y otras tantas muestras del spaghetti western.

\section{BIBLIOGRAFÍA}

Carmona, L. M. (2008). Diccionario de compositores cinematográficos. Madrid: T\&B Editores. Carmona, L. M. (2012). Música \& Cine. Las grandes colaboraciones entre director y compositor. Madrid: T\&B Editores.

Chemerka, W. R. y Wiener, A. J. (2009). The music of the Alamo: from 19th century ballads to big-screen soundtracks. Houston: Bright Sky Press.

Clark, D. y Andersen, C. P. (1995). John Wayne's The Alamo: the making of the epic film. New Jersey: Carol Publishing Group.

Edmonson, J. C. (2000). Alamo story: from early history to current conflicts. Lanham: Republic of Texas Press.

Flores, R. R. (2010). Remembering the Alamo: Memory, Modernity, and the Master Symbol. Austin: University of Texas Press.

Gevinson, A. (Ed., 1997). Within Our Gates: Ethnicity in American Feature Films, 1911-1960. Berkeley and Los Angeles: University of California Press.

Graham, D. (1985-1986). Remembering The Alamo: the story of the Texas Revolution in popular culture. The Southwest Historical Quarterly, 89, 35-66.

Groneman, W. (2007). David Crockett: Hero of the Common Man. New York: Tom Doherty Associates. 
Hansen, T. (Coord., 2003). The Alamo reader: a study in history. Mechanicsburg: Stackpole Books.

Hatch, T. (1999). Encyclopedia of The Alamo and the Texas revolution. Jefferson: McFarland \& Company.

Hatch, T. (2007). Encyclopedia of The Alamo and the Texas revolution. Jefferson: McFarland \& Company.

J. D. V. M. (1863). Diccionario militar. Madrid: Imprenta de Luis Palacios.

Justo Estebaranz, A. y Pérez García, L. (2015). Del Japón feudal al planeta Akir: Estudio comparativo de la música en "Los siete samuráis" y sus remakes americanos. En AVANCA CINEMA 2015. Avanca: Ediçoes Cine-Clube de Avanca.

Justo Estebaranz, A. y Pérez García, L. (2015). Influencias de la música para western de Dimitri Tiomkin en el spaghetti western. Ucoarte. Revista de Teoría e Historia del Arte, 4, 93-103.

Kalinak, K. (2016). Scoring the West: Dimitri Tiomkin and Howard Hawks. En Howard Hawks. New perspectives. London: Palgrave, 157-171.

Karlin, F. (1994). Listening to movies. New York: Schirmer Books.

Lafuente Alcántara, M. (1852). Historia de Granada. Tomo Segundo. París: Baudry, Librería Europea.

Langman, L. (2000). Destination Hollywood: The Influence of Europeans on American Filmmaking. Jefferson: McFarland.

Matovina, T. M. (2002). The Alamo remembered: texano accounts and perspectives. Austin: University of Texas Press.

McEnteer, J. (2004). Deep in the heart: the Texas tendency in American politics. Westport: Praeger.

McGivern, C. (2007). John Wayne. La sombra de un gigante. Madrid: Ediciones Jaguar.

Munn, M. (2003). John Wayne: the man behind the myth. New York: New American Library.

Niemi, R. (2006). History in the Media: Film and Television. Santa Barbara: ABC-CLIO.

Ordenanzas de S. M. para el régimen, disciplina, subordinación y servicio de sus exércitos. Tomo segundo. 1768. Madrid: Edición de Antonio Marín.

Österberg, B. O. (2009). Colonial America on Film and Television: A Filmography. Jefferson: McFarland.

Padrol, J. (2007). Diccionario de bandas sonoras. Madrid: T\&B Editores.

Pérez García, L. (2017). Dimitri Tiomkin y la música del western (1940-1969): contribuciones de un compositor europeo a un género genuinamente americano. Tesis Doctoral defendida el 7 de julio de 2017 en la Universidad de Sevilla.

Pérez García, L. y Justo Estebaranz, A. (2016). Harry Sukman y Sam Fuller. Música para un western de culto: Cuarenta pistolas (1957). Pasaje a la Ciencia, 18, 9-19.

Reglamento para el ejercicio y maniobras de la caballería. Volumen I. 1824. México: Impreso en la oficina a cargo de Martín Rivera.

Rowan, T. (2015). Motion Pictures From the Fabulous 1950's. Lulu.com.

Stilwell, R. J. (2007). The Fantastical Gap between Diegetic and Nondiegetic. En Beyond the soundtrack: Representing music in cinema. Berkeley: University of California Press, 184-202.

Tavernier, B. y Coursodon, J.-P. (2010). 50 años de Cine norteamericano, Vol. 2. Madrid: Akal. Thompson, F. (2001). The Alamo: A Cultural History. Dallas: Taylor Trade Publishing.

Wierzbicki, J. E. (2012). Music, sound and filmmakers: Sonic Style in Cinema. New York: Routledge.

Williams, A. (1933). A critical study of the siege of The Alamo and of the personnel of its defenders. Chapter II: Santa Anna's invasion of Texas, and his investment and final assault of The Alamo. The Southwestern Historical Quarterly, 37, 1, 1-44.

Xalabarder, C. (2006). Música de cine. Una ilusión óptica. Edición digital de Libros en Red.

Xalabarder, C. (2013). El guion musical en el cine. CreateSpace Independent Publishing Platform. 